\title{
NopU
}

ISSN: $2318-1966$

v. 4, n. 5

jan - jul 2016

Artigos

\section{PENSANDO O CAMPO CINEMATOGRÁFICO BRASILEIRO A PARTIR DAS CONTRIBUIÇÕES DE PIERRE BOURDIEU}

\author{
Ricardo Normanha Ribeiro de Almeida \\ Doutorando pelo Programa de Doutorado em Ciências Sociais do IFCH / UNICAMP. \\ Mestre em Educação pela Faculdade de Educação da UNICAMP. Bacharel em Sociologia e \\ Ciências Políticas e Licenciado em Ciências Sociais pelo IFCH / UNICAMP.
}

\begin{abstract}
RESUMO
Este artigo tem como objetivo observar e compreender a estruturação do campo cinematográfico brasileiro a partir das contribuições teóricas de Pierre Bourdieu. Os conceitos de campo e habitus são elementos chaves para esta compreensão na medida em que revelam a teoria da prática desenvolvida pelo sociólogo francês, na qual se observam as relações que se estabelecem entre os agentes do campo e as práticas sociais incorporadas. A teoria da prática busca estabelecer a mediação necessária entre as teorias sociológicas centradas nas estruturas sociais e as teorias que focalizam a ação humana. Desta forma, este artigo busca inicialmente discutir os conceitos chaves de campo e habitus para, em seguida, se debruçar sobre a análise do campo cinematográfico brasileiro por meio da compreensão, ao menos introdutória, de seus mecanismos de estruturação e conquista de autonomia, suas regras de funcionamento, suas disputas internas, bem como de sua relação com os demais campos do audiovisual e das artes.
\end{abstract}

Palavras-Chave: Teoria do campos; Campo cinematográfico; Habitus.

\section{THINKING THE BRAZILIAN CINEMATOGRAPHY FIELD FROM THE PIERRE BOURDIEU'S CONTRIBUTIONS}

\begin{abstract}
This article aims to observe and understand the structure of the Brazilian cinematography field from the Pierre Bourdieu's theoretical contributions. The concepts of field and habitus are essential elements to this understanding as to reveal the theory of practice developed by the French sociologist, in which we observe the relationships established between field agents and corporate social practices. The theory of practice aims to establish the necessary mediation between the sociological theories centered on social structures and the theories that focus on human action. Thus, this article aims to initially discuss the essential concepts of field and habitus, then look intoanalysis of the Brazilian cinematography field through the understanding of their mechanisms of structuring and achievement of autonomy, operating rules, their disputes internal andtheir relations to other fields of audiovisual and arts.
\end{abstract}

Keywords: Theory of fields; Cinematographic field; Habitus. 
NORUS - v4, n.5, jan - jul 2016.

\section{Introdução: Bourdieu e a sociologia da prática}

Uma visão panorâmica acerca da história da Teoria Sociológica contemporânea nos permite apontar para um debate central, que permeia toda esta história: a centralidade da relação entre ação e estrutura social. Pierre Bourdieu, um dos mais importantes sociólogos da contemporaneidade, não fugiu, é claro, desta problematização teórica em sua vasta obra.

A Sociologia, ao longo de sua história transita entre dois polos representados por métodos epistemológicos distintos: o objetivismo e a fenomenologia. O primeiro compreende a centralidade das relações objetivas como estruturantes das práticas individuais subjetivas, ou seja, os indivíduos aparecem como elementos condicionados pela objetividade das relações sociais e pela primazia da estrutura social. O segundo entende a relevância primordial da experiência dos indivíduos, permeada por sua subjetividade, como elemento constitutivo fundamental das relações sociais.

A Teoria da Prática de Pierre Bourdieu, ou o Conhecimento Praxiológico, como se refere Ortiz (1994), é uma tentativa do sociólogo francês em estabelecer uma conciliação e uma articulação dialética entre os dois polos método-epistemológicos. Em outras palavras, a obra de Bourdieu tenta ser a mediação entre o ator/agente e a estrutura social. Ainda que o esforço de Bourdieu seja no sentido de uma mediação, uma leitura cuidadosa da obra do autor deixa claro que em sua teoria sociológica, a estrutura social, ainda que seja construída pelos agentes, através do habitus, é também constitutiva da ação individual e coletiva dos agentes. Adiante, a elaboração mais cautelosa acerca dos conceitos de habitus e campo em Bourdieu deixará mais clara esta dimensão que acabamos de apontar.

Para desenvolver a sua sociologia da prática, Bourdieu realiza um duplo movimento em relação à contribuição filosófica de Jean-Paul Sartre. Em um primeiro momento, se aproxima do filósofo existencialista na medida em que Sartre compreende a ação individual a partir das condições concretas de vida. Na concepção sartriana, o indivíduo constrói a sua existência a partir de sua realidade vivida e é, ao mesmo tempo, produto e produtor da história. Para enfatizar esta compreensão, Sartre utiliza a noção de projeto que entende a ação humana determinada pelas relações objetivas e exteriores ao indivíduo, mas também orientada no sentido de um objetivo futuro, de um projeto (SARTRE, 1978). Esta complexa dimensão da ação humana exerce bastante influência nas elucubrações de Bourdieu. No entanto, ao invés de tomar como central a ideia de um projeto futuro, como orientador da ação, Bourdieu resgata a noção de habitus, que compreende esta mediação dialética entre ação e estrutura - não como um projeto orientado para o futuro - mas como uma articulação imediata. 


\section{Pensando no campo cinematográfico brasileiro a partir das contribuições de Pierre Bourdieu}

Neste sentido, a teoria da prática de Pierre Bourdieu pretende considerar o agente social em função das relações objetivas que estruturam a sociedade global. Compreende-se, portanto, a prática com a relação dialética entre uma situação específica e um habitus incorporado pelo agente. Segundo Ortiz,

A situação particular que enfrenta um ator social específico se encontra, portanto, objetivamente estruturada; a adequação entre o habitus e essa situação permite, desta maneira, fundar uma teoria da prática que leve em consideração tanto as necessidades dos agentes quanto a objetividade da sociedade (ORTIZ, 1994, p. 19).

É esta teoria da prática que nos permite compreender de maneira bastante precisa os processos de formação e estruturação dos campos - que iremos desenvolver em seguida - e em especial, a formação e a conquista de autonomia do campo artístico cinematográfico. Por intermédio da compreensão das ações dos agentes do campo cinematográfico, estruturadas através do habitus, determinadas socialmente e determinantes para a produção e reprodução das relações objetivas, podemos envolver alguns elementos que nos ajude a entender a constituição deste campo, suas características fundamentais, suas regras e normas de funcionamento e os interesses específicos pelos quais os agentes se mobilizam.

Neste sentido, esse artigo se divide em dois grandes eixos: o primeiro busca desenvolver os conceitos de campo e habitus a partir da contribuição teórica de Pierre Bourdieu; o segundo objetiva aproximar os conceitos apresentados da observação do campo artístico brasileiro, tendo como foco especial o campo cinematográfico, bem como a relação e os movimentos de aproximação e distanciamento deste campo com os demais campos do audiovisual, no sentido de compreender os mecanismos para sua estruturação e autonomia.

\section{Campo e habitus}

Buscando se afastar do interacionismo simbólico, importante corrente da Teoria Sociológica contemporânea, que busca uma compreensão da sociedade a partir de suas microestruturas, ou seja, nas relações sociais observadas em escala reduzida, Pierre Bourdieu amplia o campo de visão do sociólogo, uma vez que compreende que a realidade social não é mero resultado das ações e interações individuais dos agentes. Para Bourdieu é necessário estudar as relações existentes num espaço determinado, bem como levar em conta as estratégias de transformação ou conservação colocadas pelos agentes. Neste sentido, o campo se define como o espaço onde as posições dos agentes estão predeterminadas; trata-se do locus onde ocorre a luta concorrencial entre os atores 
NORUS - v4, n.5, jan - jul 2016.

sociais em torno de interesses específicos (ORTIZ, 1994); trata-se, também do lugar de produção do espaço social e das relações objetivas (BOURDIEU, 2000). Nesta mesma direção, o conceito de campo nos faz distanciar tanto das explicações totalizantes a partir do exterior - como nos apresenta a teoria social de Durkheim - quanto das teorias reducionistas - como a fenomenologia e o interacionismo simbólico inspirados pela teoria social de Weber.

Os campos, segundo Bourdieu (1983), enquanto espaços estruturados de posições dos agentes, possuem leis gerais de funcionamento; estas leis, invariantes, quando observadas em um campo particular, nos ajudam a compreender os outros campos. As especificidades de cada campo contribuem para uma formulação mais geral sobre a teoria dos campos e, portanto, para uma elaboração teórica mais ampla. Assim, podemos dizer que, para Bourdieu, a micro e a macro teoria, a pesquisa empírica e as teorias gerais andam juntas e se complementam.

Neste sentido, percebe-se também uma tentativa do sociólogo francês em se distanciar do reducionismo econômico levado a cabo por correntes do marxismo ortodoxo. Deste modo, a teoria dos campos de Bourdieu não pressupõe a hierarquização das diversas esferas da sociedade de modo fixo; tampouco considera uma teoria como fundadora das demais. Em outro sentido, Bourdieu procura apontar para o fato de que uma teoria se encontra situada em um campo específico da sociedade e contribui para a compreensão mais ampla dos campos. A teoria econômica não é fundadora; algumas características do campo econômico são comuns aos demais campos e nos ajudam a elaborar uma teoria geral dos campos.

Para Bourdieu,

A teoria geral da economia dos campos permite descrever e definir de forma específica de que se revestem, em cada campo, os mecanismos e os conceitos mais gerais (capital, investimento, ganho), evitando assim todas as espécies de reducionismo, a começar pelo economicismo, que nada mais conhece além do interesse material e a busca da maximização do lucro monetário (BOURDIEU, 2000, p. 69).

Um campo se define pelos objetos específicos de disputas entre seus agentes. Desta forma, "cada categoria de interesses implica na indiferença em relação a outros interesses, a outros investimentos" (BOURDIEU, 1983, p.89). O funcionamento do campo depende dos objetos em disputa e de agentes dispostos a disputar. Para tanto, é necessário que os agentes devam ter conhecimento e reconhecimento das leis imanentes da disputa. Este conhecimento e reconhecimento do funcionamento do campo por parte dos agentes relaciona-se ao conceito de habitus. O habitus é condição de funcionamento do campo e, ao mesmo tempo, produto deste funcionamento. Trata-se do capital de técnicas, referências, conjunto de crenças necessários para que os agentes possam agir de forma compatível com as regras do campo (BOURDIEU, 1983). Em outras palavras, o habitus é um acumulado de aprendizados passados - e neste ponto Bourdieu 


\title{
Pensando no campo cinematográfico brasileiro a partir das contribuições de Pierre Bourdieu
}

reafirma seu distanciamento com a ideia de "projeto futuro" de Sartre - que conforma e orienta a ação, que produz e reproduz as relações sociais e que é engendrado pelas relações sociais (ORTIZ, 1994). Nas palavras do próprio autor, o habitus define-se por um "sistema de disposições duráveis, estruturas estruturadas predispostas a funcionarem como estruturas estruturantes" (BOURDIEU, 1994, p. 61).

$\mathrm{Na}$ teoria bourdieusiana, os atores interiorizam os valores e normas sociais, bem como os sistemas de classificação preexistentes, assegurando a adequação entre as ações do sujeito e a realidade objetiva. Neste sentido, a eficácia de uma ação já se encontra previamente conformada na própria estrutura social. Segundo Ortiz,

\begin{abstract}
A possibilidade da ação se exercer se encontra, assim, objetivamente estruturada, sem que disto decorra uma obediência às regras (Durkheim), ou uma previsão consciente das metas a serem atingidas (Weber). (...) ele [Bourdieu] propõe uma teoria da prática na qual as ações sociais são concretamente realizadas pelos indivíduos, mas as chances de efetivá-las se encontram objetivamente estruturadas no interior da sociedade global (ORTIZ, 1994, p.15).
\end{abstract}

Assim, o conceito de habitus na teoria sociológica de Bourdieu pressupõe a sua manifestação social, por parte do grupo ou classe, e também individual, como processo de internalização da objetividade por parte do agente. Nesta direção, Bourdieu propõe enfatizar o estudo do modo de estruturação do habitus através das instituições de socialização, bem como reforçar a ideia de que a história individual de um ator é uma "variante estrutural" do habitus do grupo ou classe ao qual pertence o indivíduo. Ao analisarmos o campo a partir do conceito de habitus, podemos compreender as rupturas e permanências deste campo, ou seja, entender as relações existentes no interior de um campo como disputa entre os agentes localizados em dois polos opostos: dominantes e dominados. Para Ortiz,

O campo se particulariza, pois, como um espaço onde se manifestam as relações de poder, o que implica afirmar que ele se estrutura a partir da distribuição desigual de um quantum social que determina a posição que um agente específico ocupa em seu seio. Bourdieu denomina esse quantum de "capital social" (ORTIZ, 1994, p. 21).

A estrutura de um campo e as práticas dos agentes exigem a criação de marcas de distinção. Para Bueno (2003) "Aqueles que se distinguem marcam época no campo e, consequentemente, adquirem um capital social dominante" (BUENO, 2003, p. 74). Neste sentido, a noção de capital social deve ser enfatizada:

O capital social é o conjunto de recursos atuais ou potenciais que estão ligados à posse de uma rede durável de relações mais ou menos institucionalizadas de interconhecimento e de interreconhecimento ou, em outros termos, à vinculação a um grupo, como conjunto de agentes que não somente são dotados de propriedades comuns (...), mas também são unidos por ligações permanentes e úteis (BOURDIEU, 2002, p.67). 
NORUS - v4, n.5, jan - jul 2016.

Diante desta estrutura do campo, os agentes localizados no pólo de dominância possuem o máximo de capital social e utilizam estratégias de conservação da estrutura do campo. Para Bourdieu, a prática destes agentes é considerada ortodoxa. Por outro lado, os agentes localizados no pólo dominado do campo carecem de grandes acúmulos de capital social específico ${ }^{1}$ e suas estratégias de ação são orientadas no sentido da subversão da estrutura do próprio campo. Tratam-se de ações heterodoxas, ou heréticas, conforme a teoria bourdieusiana. Não há, portanto, neutralidade das ações no interior do campo pois "toda realização pressupõe necessariamente uma série de interesses (os mais diversos) em jogo" (ORTIZ, 1994, p.22).

Vale reforçar, porém, que a heterodoxia, ou as estratégias heréticas, ainda que contestem o acúmulo de capital social dos dominantes, não contestam, à rigor, a própria estrutura do campo. A contestação se dá em nível simbólico e ritual. A heresia, em última instância, reforça a própria ordem do campo ao passo que todos os agentes do campo (dominantes e dominados) possuem certo número de interesses fundamentais em comum e compartilham das mesmas regras do jogo.

Bourdieu explica essa "cumplicidade objetiva" afirmando que "Os que participam da luta contribuem para a reprodução do jogo contribuindo (mais ou menos completamente dependendo do campo) para reproduzir a crença no valor do que está sendo disputado” (BOURDIEU, 1983, p.91). Indo além, Bourdieu propõe relacionar as posições assumidas pelos agentes de um campo específico com as posições ocupadas por eles na estratificação global da sociedade. Desta maneira, na ótica da teoria sociológica de Bourdieu, a ortodoxia tende a produzir e reproduzir os bens simbólicos que se adequam aos valores da classe, ou fração de classe dominante, ao passo que a heterodoxia tende a produzir e reproduzir os bens simbólicos que se alinham a outras classes e frações de classe não dominantes. Em suma, "As relações de poder no interior do campo reproduzem, assim, outras relações que lhe são externas” (ORTIZ, 1994, p. 24).

\section{O campo das artes e do cinema}

Pierre Bourdieu, em sua obra do início dos anos de 1990 As Regras da Arte - Gênese e Estrutura do Campo Literário, desenvolve uma rica contribuição para a compreensão do surgimento do campo literário na França. Como a própria teoria sociológica de Bourdieu enfatiza, um estudo pormenorizado das estruturas e regras de funcionamento de um campo específico contribui em larga medida para a elaboração de uma teoria geral dos campos. Desta forma, a partir

\footnotetext{
${ }^{1}$ Bourdieu considera como capital específico todo aquele capital válido para determinado campo. Isso não quer dizer que este mesmo capital social não seja válido também em outro campo, mas sim que dentro das especificidades daquele campo específico, tal capital social assume grande relevância.
} 


\section{Pensando no campo cinematográfico brasileiro a partir das contribuições de Pierre Bourdieu}

de agora, o esforço deste artigo será o de trazer alguns apontamentos que possam contribuir para a compreensão do surgimento e da estrutura do campo cinematográfico a partir da leitura e da articulação de conceitos presentes na obra de Bourdieu.

Um dos aspectos de maior importância para a compreensão do campo cinematográfico consiste no entendimento da ideia de subordinação estrutural. Bourdieu, ao se referir ao processo crítico de conquista de autonomia do campo literário, aponta para o fato de que este campo esteve (e, em certa medida, permanece) subordinado a outros campos, sobretudo o campo econômico. O mesmo podemos dizer em relação ao campo cinematográfico. Poucas coisas iluminam tanto a burguesia quanto a técnica, a máquina e a racionalidade. É neste contexto que surge o cinema como espetáculo e como mercadoria: uma arte criada pela burguesia e que se apóia fundamentalmente numa máquina, que exige técnica especializada para o seu manuseio. Nesta junção de arte e técnica cria-se uma ilusão de realidade, marca registrada do universo das imagens em movimento; mas ao mesmo tempo cria-se outra ilusão: o cinema é uma arte objetiva, neutra, sem interferência humana (BERNARDET, 1980).

No entanto, entender o cinema como simples reprodução objetiva da realidade e sem intervenção do homem, é o mesmo que desconsiderar os indivíduos que fazem o cinema: o diretor ou autor que pensa o argumento e o roteiro; o operador de câmera que manuseia a máquina, provido de um conhecimento técnico, mas também de uma sensibilidade artística. Pensar o cinema como pura técnica, como arte neutra e objetiva, elimina a noção de classe, ou pelo menos do fragmento de classe que está por trás da realização do filme.

Esta concepção de cinema, muito característica de seus primórdios, faz parte de um construto ideológico que atende a uma perspectiva de legitimação da dominação de classe. Afinal, a classe dominante apresenta sempre sua ideologia como verdade, e nunca como ponto de vista. Assim, o cinema aparece como um intenso campo de disputa para fazer aparecer quem fala. Em outras palavras, esta concepção de neutralidade da arte cinematográfica se relaciona diretamente com a ideia de ortodoxia presente nas práticas dos agentes do campo, localizados no pólo dominante. Relaciona-se igualmente com a ideia de que os bens simbólicos produzidos pela lógica ortodoxa do campo reproduzam os valores e anseios representados pela posição dos agentes dominantes na estratificação da sociedade.

Para Bourdieu, o campo literário só consegue se consolidar e se tornar autônomo, ao passo que se afasta dos campos econômico e político. Para o autor, esta consolidação se efetiva em função 
NORUS - v4, n.5, jan - jul 2016.

da negação dos valores representados pela burguesia e que imperam nestes campos ${ }^{2}$. Neste sentido, a autonomia do campo literário se deu através de um processo no qual a arte produzida pelo campo restringia-se ao próprio campo. Em outras palavras, a circulação das obras literárias permanecia limitada aos demais agentes do mesmo campo literário. Assim, “(...) estamos com efeito num mundo econômico de pernas para o ar: o artista só pode triunfar no terreno simbólico perdendo no terreno econômico (pelo menos a curto prazo), e inversamente (pelo menos a longo prazo)" (BOURDIEU, 1996, p.105). Porém, o que distancia o campo literário do campo cinematográfico é que a literatura, enquanto prática artística organizada, é anterior à burguesia, à racionalidade moderna e ao desenvolvimento do capitalismo. O cinema, por outro lado, se consolida de forma organizada em torno do espetáculo da produção e projeção das imagens em movimento a partir da racionalidade burguesa, mantendo-se, desde então, atrelada a ideia de mercadoria, subordinada ao campo econômico ${ }^{3}$. Nesse sentido, a obra fílmica é considerada uma mercadoria abstrata, mas que deve atender à lógica de um produto que deve ser vendido no mercado. Por isso, em sua concepção industrial, demanda um sistema de trabalho que envolve muitos profissionais especializados e, portanto, uma específica divisão do trabalho.

Nas análises sobre a relação do cinema com o mercado e o campo econômico, Pierre Sorlin (1985) nos indica duas possibilidades de caminhos: o primeiro nos leva à compreensão do cinema apesar de sua base industrial, ou seja, o cinema como uma expressão artística dependente de um esquema de produção industrial. Este tipo de enfoque pressupõe a nítida separação entre os que financiam e os que fazem a obra cinematográfica. No entanto, para Sorlin, esses dois lados não podem ser colocados em oposição. Disso resulta o segundo caminho de análise, que pensa o cinema como um produto essencialmente industrial e que depende de dois fatores: dinheiro e ofício. Não se pode, portanto, entender um filme deslocado de sua origem econômica.

Pierre Sorlin (1985) aproxima-se, ao falar sobre o cinema, do conceito bourdieusiano de campo, ainda que não se refira diretamente a ele. Para o autor, a ideia de campo remete à presença simultânea de vários grupos, permeados por um conjunto de relações parcialmente conflitantes, em que se transparecem movimentos de diferenciação e alinhamento. Este conceito de campo

\footnotetext{
${ }^{2}$ Vale ressaltar que o período a que se refere este processo de luta por autonomia do campo literário é também o período no qual se desenvolvem inúmeros desdobramentos do processo revolucionário iniciado no século XVIII na França, ou seja, trata-se de um momento histórico bastante peculiar no qual a burguesia, recém chegada ao controle do poder político, ainda buscava se estabelecer enquanto classe dominante e o modo de produção capitalista ainda se estruturava. ${ }^{3}$ Vale destacar a contribuição de Arlindo Machado (MACHADO, Arlindo. Pré-cinemas \& pós-cinemas. 6. ed. Campinas, SP: Papirus, 2011) no que tange o debate em torno das origens do cinema enquanto prática artística associada ao seu desenvolvimento técnico-científico. Para o autor, o cinema existe antes mesmo de se consolidar enquanto arte de espetáculo e antes mesmo do aprimoramento técnico dos equipamentos considerados - por parte considerável da literatura - como inaugurais do cinema, em especial, o cinematógrafo desenvolvido pelos irmãos Lumière.
} 


\section{Pensando no campo cinematográfico brasileiro a partir das contribuições de Pierre Bourdieu}

complementa a visão do cinema enquanto modo de produção industrial e suas diferentes formas de dominação, pois nesta perspectiva, toda prática cultural é uma prática de diferenciação através do domínio dos meios específicos de cada campo da cultura. Neste sentido, o que se apresenta é o reconhecimento do conjunto social ao direito exclusivo do grupo especializado em determinada prática cultural. Além disso, este conjunto cinematográfico deve ser percebido como uma unidade social e o filme como uma obra resultante do trabalho de uma imensa equipe, que por sua vez participa também de outros campos: o próprio meio do cinema; o meio das pessoas interessadas em cinema (e que não necessariamente são agentes diretos da produção cinematográfica); e da sociedade global.

O campo cinematográfico demonstra também forte capacidade de integração interior. Para Bourdieu esta integração está relacionada com as estratégias de investimento social orientadas para a construção de relações sociais úteis e necessárias para o próprio campo, "aptas a proporcionar lucros materiais ou simbólicos" (BOURDIEU, 2002, p.68). A reprodução de hábitos e costumes adquiridos do passado, dos membros mais antigos deste meio, passa a ser regra natural deste campo.

A “norma" cinematográfica, ou seja, o fazer prático do cinema, nada mais é do que a média das práticas correntes deste meio, segundo a análise de Sorlin (1985). Esta máxima vale, sobremaneira, para os filmes que se propõem a seguir mais detidamente à lógica da comercialização. "O melhor meio de obter o crédito necessário para um filme comercial é seguir as práticas de um meio que se nutre de quase todas as formas de financiamento" (SORLIN, 1985, p.91). No entanto, ainda para este autor, grande parte dos mecanismos de coesão e unidade interna do campo cinematográfico resulta de uma aparente solidariedade interna contra os agentes exteriores ao campo, mas que participam também do processo de produção, como os Bancos e o próprio Estado.

\footnotetext{
O essencial está em outro lugar. O excesso de oferta (muitos filmes para a clientela existente), a separação radical entre a produção e a comercialização fazem com que os estúdios vivam o temor permanente do desemprego. Diante dos banqueiros, do Estado, cujo apoio determina a maior parte das filmagens, todos os que participam da realização se sentem solidários. A anarquia da produção implica na neutralização parcial do campo cinematográfico, e faz nascer a ilusão de um meio refratário às lutas sociais. Se existe um inimigo, ele é sempre de fora (SORLIN, 1985, p. 93).
}

Numa leitura bourdieusiana, podemos relacionar esta aparente solidariedade interna dos agentes do campo com o conceito de "cumplicidade objetiva" (BOURDIEU, 1983) o qual compreende que os agentes do campo, apesar dos antagonismos, possuem certo número de interesses fundamentais em comum. 
NORUS - v4, n.5, jan - jul 2016.

\subsection{O campo cinematográfico no Brasil}

O campo cinematográfico brasileiro, segundo Bueno (2003), adquire sua autonomia em relação aos outros campos com o advento do Cinema Novo, no início dos anos de 1960. A autonomia do campo está relacionada com sua capacidade de impor sua lógica própria de funcionamento diante dos outros campos. E a luta pela autonomia do campo cinematográfico nacional se caracteriza pelas disputas de seus agentes pela permanência ou subversão de sua estrutura e também pela disputa com outros campos da cultura e das artes. Para a autora, até a consolidação efetiva do campo cinematográfico brasileiro, os agentes deste campo - os cineastas circulavam em outros campos de poder, como o campo da cultura, do jornalismo e da literatura. Uma forte característica do campo cinematográfico brasileiro foi sua legitimação concedida pelos seus próprios agentes, que se descobrem e se inventam enquanto cineastas.

Os diversos campos do audiovisual brasileiro se desenvolvem isoladamente ao longo da história. $\mathrm{O}$ incremento da indústria cultural brasileira não favoreceu a interligação dos campos da televisão, publicidade, cinema, música, etc. Na verdade, com exceção do cinema, os diversos campos tiveram maior diálogo entre si. Não podemos pensar no desenvolvimento da televisão e do rádio sem a publicidade, por exemplo (MARSON, 2009).

É importante também destacar o papel do Estado no desenvolvimento da indústria audiovisual. No caso da televisão e publicidade, até pela forte ligação entre elas, o estímulo estatal contribuiu para que estes campos pudessem ter garantias de sustentabilidade. Por outro lado, o cinema nacional nunca conseguiu se desvencilhar da tutela do Estado, impedindo a consolidação de uma indústria cinematográfica independente e capaz de garantir sua própria manutenção. Caracteriza-se, neste sentido, a nítida subordinação estrutural do campo cinematográfico brasileiro em relação ao campo político, como ressalta Bourdieu ao se referir ao campo literário.

Para Bourdieu (1996), no campo artístico ${ }^{4}$ convivem duas formas antagônicas de produção de arte. De um lado temos a "arte-pura", que participa de uma esfera econômica antieconômica, que representa um ciclo de produção longo e que não atende a uma demanda imediata de consumo, ou seja,

\footnotetext{
${ }^{4} \mathrm{O}$ percurso teórico elaborado por Pierre Bourdieu em As regras da arte nos leva a compreender de forma bastante clara a noção de que o entendimento de elementos fundamentais do campo literário pode nos servir para a compreensão de outros campos. Isto fica bastante nítido no trecho: "O leitor poderá, ao longo de todo esse texto, substituir escritor por pintor, filósofo, cientista, etc. e literário por artístico, filosófico, científico, etc. (...) Tal não significa que ignoremos as diferenças entre os campos. Assim, por exemplo, a intensidade da luta varia sem dúvida segundo os gêneros, e segundo a raridade da competência específica que estes exigem em cada época, quer dizer segundo a probabilidade da 'concorrência desleal' ou do 'exercício ilegal' (o que explica sem dúvida que o campo intelectual, incessantemente sob a ameaça da heteronomia e dos produtores heterônomos, seja uma dos lugares privilegiados para a apreensão da lógica de lutas que assombram todos os campos)." (BOURIDEU, 1996, pp. 246-247).
} 
(...) esta produção que não pode reconhecer outra procura senão a que ela própria é capaz de produzir, mas apenas a longo prazo, orienta-se para a acumulação de capital simbólico, como capital "econômico" negado, reconhecido, e portanto legítimo, verdadeiro crédito capaz de garantir, em certas condições e a longo prazo, lucro "econômico" (BOURDIEU, 1996, p.169).

Do lado oposto, temos a "arte-mercadoria", que participa da lógica da economia industrial, com ciclo de produção curto e que se orienta para uma clientela e uma demanda já conhecidas. Nas palavras do autor, “(...) fazendo do comércio dos bens culturais um comércio como os outros, conferem prioridade à difusão, ao sucesso imediato e temporário, medido, por exemplo, pelas tiragens, e se contentam com ajustar-se à procura preexistente da clientela (...)" (BOURDIEU, 1996, p. 169).

Nesta mesma direção, é muito forte no pensamento cinematográfico brasileiro a concepção do filme como arte - neste caso, como "arte-pura" -, o que contribuiu para o afastamento do cinema dos outros campos mais "comerciais". Nota-se o mesmo que Bourdieu aponta em As Regras da Arte, quando distingue a produção cultural voltada para o acúmulo de capital econômico da produção orientada para o acúmulo de capital simbólico. Assim,

A união entre os três campos (cinema, televisão e publicidade) para a formação de uma
indústria cultural audiovisual no Brasil, embora já estivesse presente nas discussões entre
produtores e Estado desde a década de 1970 , sempre foi postergada. O cinema se
desenvolveu a margem dessa indústria cultural nascente nos anos 60 e 70 , e os cineastas
apresentaram muita dificuldade em se perceberem como parte do mercado audiovisual.
(MARSON, 2009, p.93-94)

Na estruturação do campo cinematográfico no Brasil percebe-se claramente a disputa entre os agentes voltados a uma produção cujo objetivo é o acúmulo de capital econômico ${ }^{5}$ e os agentes cujas produções se orientam para consolidação de um capital simbólico. Para estes últimos, o que vale é "criar um nome", uma vez que um sucesso que seja apenas comercial é efêmero; o interesse específico do campo artístico consiste na consagração do nome do artista, ou seja, no acúmulo de capital simbólico. Ainda segundo Marson (2009), no Brasil, o campo do cinema se mistura com o campo erudito, submetido mais às regras da arte do que às regras da acumulação econômica, sobretudo até meados nos anos 80 .

No campo cinematográfico, esta convivência entre "arte-pura" e "arte-mercadoria" se traduz na eterna disputa simbólica localizada no debate que dominou a literatura específica sobre o tema, acerca da autoria no cinema. Mais precisamente, na querela entre "cinema de autor" e "cinema industrial”. A "política dos autores", como ficou conhecida, foi um movimento iniciado na França,

\footnotetext{
${ }^{5}$ Vale ressaltar a advertência pautada pelo autor: "O capital econômico só pode garantir os lucros específicos proporcionados pelo campo (...) se se reconverter em capital simbólico” (BOURDIEU, 1996, p. 177)
} 
NORUS - v4, n.5, jan - jul 2016.

no início da década de 1950, que trouxe à tona uma discussão bastante pertinente para o campo cinematográfico: quem assina a obra de arte cinematográfica? Este debate travado, presente na revista especializada Cahier Du Cinèma buscou resgatar a figura do diretor enquanto autor da obra fílmica. Assim, defendia-se a ideia de que mesmo quando um diretor não assina o roteiro ou o argumento do filme, ele assume, quase sempre, a decupagem, a filmagem, a montagem, orientação ao fotógrafo, etc., estabelecendo, desta forma, uma multiplicidade de funções centradas na figura do diretor. A princípio, esta discussão sobre o cinema de autor ficou mais restrita ao cinema europeu, já que a racionalidade industrial do cinema norte-americano não permitia condições para este tipo de debate.

A noção de autor no cinema é substancialmente ligada à ideia de escritor. O filme é para o diretor o que o livro é para o escritor. No entanto, esta discussão não dá conta de compreender o cinema como um campo específico, localizado em uma posição singular no campo de poder, onde agentes atuam de forma a garantir a própria existência do campo. Dito de outra forma, a polêmica em torno do tema da autoria no cinema pode ser muito bem compreendida pela luta entre dois princípios organizadores do campo.

(...) cada um visa impor os limites do campo mais favoráveis aos seus interesses ou, o que vem a dar no mesmo, a definição das condições da verdadeira pertença ao campo (ou dos títulos que dão direito ao estatuto de escritor, de artista ou de cientista) sendo esta a mais capaz de justificar a existência do campo tal como de facto ele existe (BOURDIEU, 1996, p.255).

A luta interna do campo entre estes dois princípios organizadores é também uma luta pela própria definição do campo, uma disputa pelo monopólio do poder de consagração dos produtos e dos produtores.

\section{Considerações finais}

As contribuições da teoria da prática de Pierre Bourdieu abrem caminhos e possibilidades para a análise e compreensão da estruturação do campo cinematográfico no Brasil, ao passo que fazem vir a tona as imbricadas relações entre os agentes dos campos artísticos e as estruturas sociais que configuram os limites para a ação destes agentes. Nesse sentido, o campo cinematográfico brasileiro se consolida a partir de uma dupla dimensão: por um lado o campo toma corpo a partir do reconhecimento de seus agentes enquanto cineastas e, portanto, a partir de um processo de distinção de suas práticas sociais em relação aos demais campos da cultura; por outro lado, o campo cinematográfico ganha autonomia ao mesmo tempo em que se mantém subordinado aos campos político e econômico ou, em outras palavras, dependente da tutela estatal e das demandas do mercado. Associada a esta segunda dimensão, o campo cinematográfico está permeado ainda por 
Pensando no campo cinematográfico brasileiro a partir das contribuições de Pierre Bourdieu

dicotomias internas, sobretudo no que tange a sua finalidade artística. Desta forma, caracteriza-se como a própria estrutura - estruturada e estruturante - do campo cinematográfico a disputa entre seus agentes pela hegemonia de uma produção artística "pura" ou pela produção de "artemercadoria".

As reflexões presentes neste artigo pretendem, antes, iluminar caminhos para novas compreensões das atividades cinematográficas no Brasil. Não se trata aqui, de encerrar o assunto, muito menos proferir conclusões mágicas que busquem desvendar o complicado processo de estruturação da produção cinematográfica nacional. Vale ainda ressaltar que o cinema no Brasil e, portanto, o próprio campo cinematográfico brasileiro, não pode ser compreendido isoladamente, uma vez que a presença do produto estrangeiro - sobretudo estadunidense, nas últimas décadas - é marca fundamental do nosso mercado de filmes. Desta forma, a busca pela compreensão sistemática do campo cinematográfico no Brasil passa, necessariamente, pela compreensão da consolidação e estruturação dos campos cinematográficos internacionais, bem como dos demais campos da cultura. Em vista da latente subordinação do campo do cinema aos campos político e econômico, deve ser levado em conta, ainda, a forte rede que liga de maneira assimétrica e desigual os mercados econômicos mundiais, inclusive no que tange os mercados de arte.

\section{Referências Bibliográficas}

BERNARDET, Jean-Claude. O que é cinema. Coleção Primeiros Passos. São Paulo: Editora Brasiliense, 1980.

BOURDIEU. Pierre. Escritos de Educação. Petrópolis: Vozes, 2002.

Questões de Sociologia. Rio de Janeiro: Editora Marco Zero Ltda, 1983.

. O Poder Simbólico. Rio de Janeiro: Bertrand Brasil, 2000.

. Esboço de uma teoria da prática. In: ORTIZ, Renato. (Org.) A Sociologia de Pierre Bourdieu. São Paulo: Editora Ática, 1994.

Presença, 1996.

As Regras da Arte - Gênese e Estrutura do Campo Literário. Lisboa: Editorial

BUENO, Zuleika de Paula. Campo e habitus: uma contribuição da sociologia de Pierre Bourdieu aos estudos cinematográficos. In: CATANI, Afrânio M. [et al.] (org.). Estudos Socine de Cinema: ano IV. São Paulo: Editora Panorama, 2003.

MARSON, Melina Izar. Cinema e Políticas de Estado: da Embrafilme à Ancine. Coleção: Indústria Cinematográfica e Audiovisual Brasileira. Vol. I. São Paulo: Escrituras Editora, 2009. 
NORUS - v4, n.5, jan - jul 2016.

ORTIZ, Renato. (Org.) A Sociologia de Pierre Bourdieu. São Paulo: Editora Ática, 1994.

SORLIN, Pierre. Sociologia del cine. Fondo de Cultura Econômica: México, 1985. 